\title{
HYBRID SYSTEM TO IMPROVE FUEL ECONOMY IN BUS APPLICATIONS
}

Patrick Matiazzo, Flavio G. Lehmann, Adriano Piletti e Marcus Vinicius Sanches De Carvalho

\author{
Cummins Brasil Ltda
}

Agrale S.A

Siemens Ltda

E-mails: patrick.matiazzo@hotmail.com, flavio.g.lehmann@hotmail.com, apiletti@agrale.com.br e marcus.carvalho@siemens.com

\begin{abstract}
Currently there is a movement to reduce emissions, fuel consumption and noise, as well as to improve driveability and start ability in bus applications; therefore hybrid vehicles have been a highlight in this new market niche in the recent years. This paper describes the integration between Cummins engines and Siemens electrical motors and systems, which are being connected in serial to meet this challenge.

The electric motors are powered by capacitors and provide power to the wheels. The controller system monitors the charge in the capacitors according to the usage demand, specific driving conditions and other factors. Based on these, it will operate the engine at the speed that will recharge the system with the best fuel consumption.

The hybrid system would use 10-30\% less fuel, even using the braking system which also provides charge for the capacitor bank. Another great advantage is the use of the braking regeneration and combustion engine to generate energy for the capacitors, thus the system is able to turn off the engine when the capacitors are charged, and consequently fuel and emissions will be zero. This additionally brings improvements in driveability while providing the expected levels of passenger comfort.
\end{abstract}

\section{INTRODUCTION}

In Brazil, vehicles are responsible for $40 \%$ of carbon dioxide $\left(\mathrm{CO}_{2}\right)$ emissions in the country. These emissions contribute to air pollution and the greenhouse effect [1].

Figure 1 shows how $\mathrm{CO}_{2}$ emissions have increased during the last 40 years from $60^{*} 10^{6}$ to $265^{*} 10^{6}$ tons. 


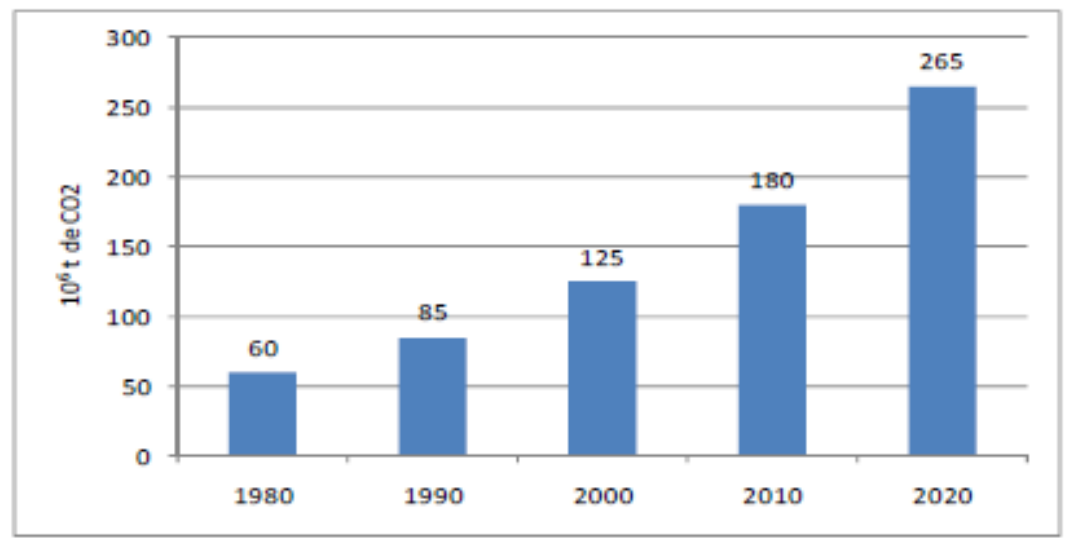

Source: Inventário Nacional de Emissões Atmosférica por Veículos Automotores Rodoviários - MMA

Figure 1: $\mathrm{CO}_{2}$ emissions from Brazilian vehicles [2]

Figure 2 shows how, in relation to other fuels, diesel has a large percentage contribution of around $50 \%$.

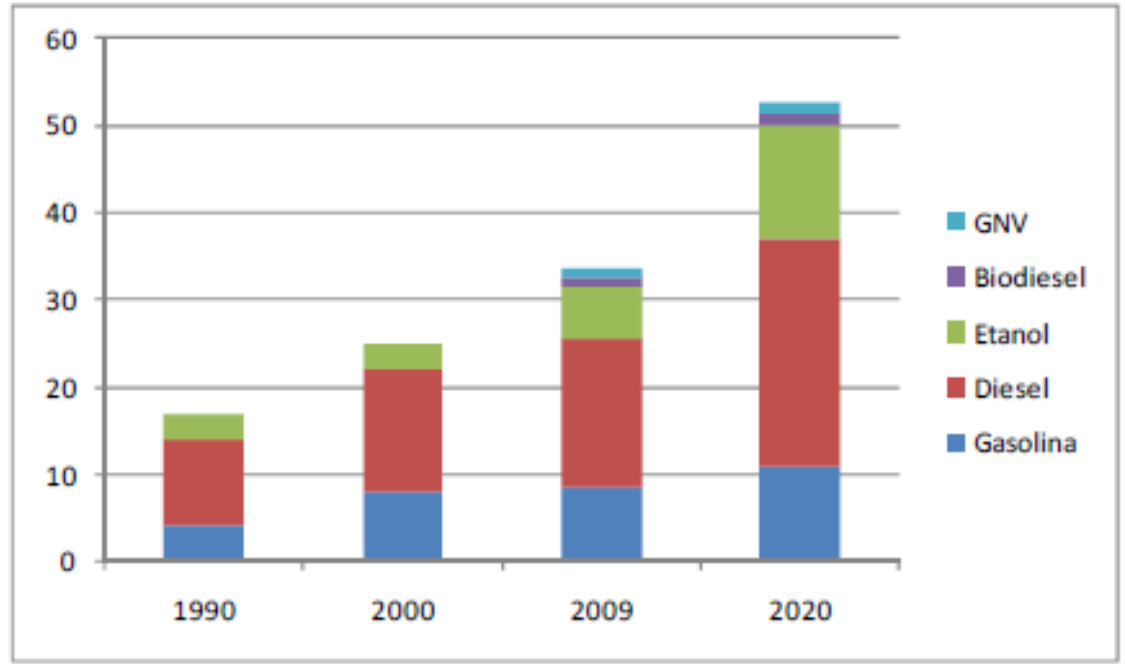

Source: Inventário Nacional de Emissões Atmosférica por Veículos Automotores Rodoviários - MMA

Figure 2: $\mathrm{CO}_{2}$ emissions from Brazilian vehicles (by fuel type) [2]

The automotive fleet in the state of São Paulo in December 2011 was approximately 13.6 million vehicles, of which 9 million were passenger cars, 1.6 million were light commercial vehicles, 500 thousand were buses and trucks, and 2.5 million were motorcycles [4].

Air pollution is one of the most serious threats to the quality of life. Emissions caused by vehicles carry various toxic substances which can cause several negative effects on health; mainly the respiratory system [4]. Emissions can be divided in different gases: 
- Carbon monoxide (CO);

- Nitrogen oxides $\left(\mathrm{NO}_{\mathrm{x}}\right)$;

- Hydrocarbons (HC);

- Sulphur oxides $\left(\mathrm{SO}_{\mathrm{x}}\right)$;

- Particulate matter (PM).

Carbon monoxide (CO) is an odourless, colourless and tasteless substance. It causes a reduction in blood oxygenation.

Nitrogen oxides $\left(\mathrm{NO}_{\mathrm{x}}\right)$ are a combination of nitrogen and oxygen formed in a combustion chamber at high temperature. $\mathrm{NO}_{\mathrm{x}}$ gases react to form smog and acid rain.

Hydrocarbons (HC) are present in unburnt or partially burnt fuel, which is expelled by the engine. Some types of hydrocarbons react in the atmosphere to form smog.

Sulphur oxides $\left(\mathrm{SO}_{\mathrm{x}}\right)$ are dense, colourless, non-flammable, highly toxic gases, and inhaling them can be a severe irritant.

Soot (solid and liquid particulates) is also known as particulate matter (PM). Due to its small size, it remains suspended in the atmosphere and can penetrate the body's defence system, reaching the pulmonary alveoli and causing:

- Malaise;

- Irritation of the eyes, throat and skin;

- Headache, nausea;

- Bronchitis;

- Asthma;

- Lung cancer.

The transportation sector in Brazil was responsible for $27 \%$ of the total consumption of energy in 2007 and, consequently, is the most important segment among the consumers of oil and derivatives, being responsible for $50.5 \%$ of this consumption, as shown in figure 3 .

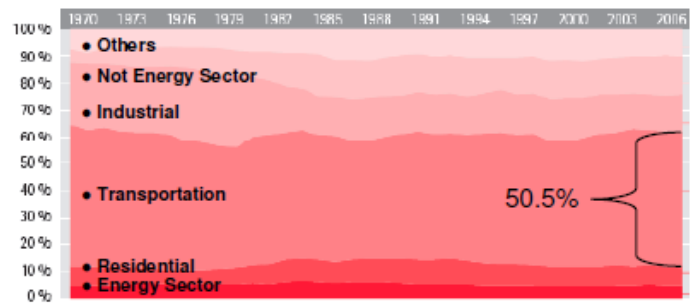

Figure 3: Consumption of oil derivatives (by sector) [4]

The demand for more powerful vehicles with lower fuel consumption is increasing more and more at present. The greater the power of the vehicle, the higher the fuel consumption, and thus the hybrid vehicle is a viable option, having the same or higher power as other vehicles but with a lower fuel consumption.

The regenerative braking provides a great advantage in large cities with car traffic because most of the energy is transformed into electrical energy, which is fed to the capacitors, thus 
reducing fuel consumption and improving transient operation through effective power management.

When a vehicle has more than one source of energy for propulsion of a different nature, it can be classified as a hybrid vehicle [1].

\section{TYPES OF HYBRIDS}

There are three different configurations for a hybrid automobile:

- Parallel Hybrid - The internal combustion engine is responsible for the movement of the automobile and the electric one is an extra aid to improve its performance. This system allows both the engine and electric motors to deliver power directly to drive the wheels through a mechanical coupling; thus it involves a parallel system installation which is more complex [4]. Shown in figure 4.

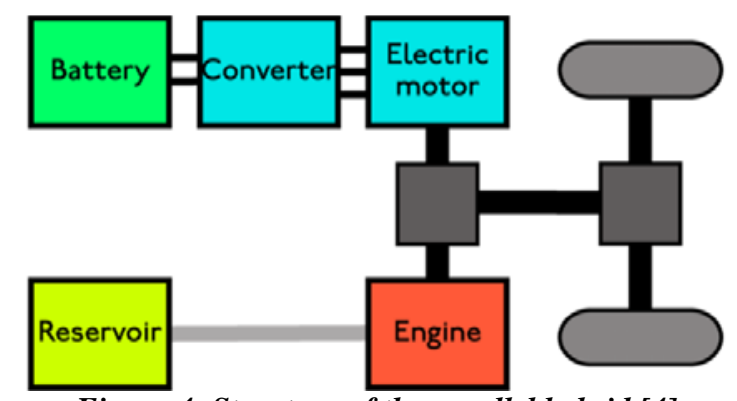

Figure 4: Structure of the parallel hybrid [4]

- Series Hybrid - The electric engine is responsible for the movement of the automobile, since the internal combustion engine only puts into motion a generator responsible for generating the energy necessary for the automobile to move itself and to load the batteries or capacitors [4]. Shown in figure 5.

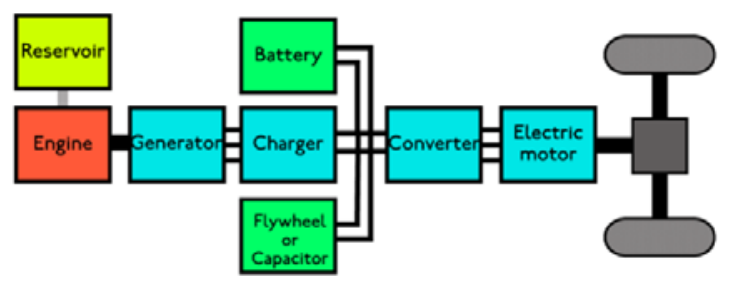

Figure 5: Structure of the series hybrid [4]

- Series-Parallel Hybrid - This has the combination of the characteristics of the system in series with the parallel system, with the objective to maximize the benefits of both. This system allows the supply of energy to the wheels and to generate electricity simultaneously, using a generator, differently to what occurs in the simple parallel configuration. It is possible to use only the electrical system, depending on the load conditions, or to use both systems at the same time, but it requires the use of an additional electric machine and a planetary unit which makes the drivetrain more complicated and costly [4]. Shown in figure 6. 


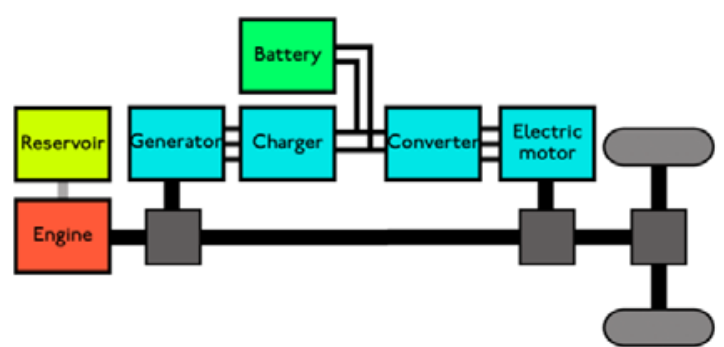

Figure 6: Structure of the series-parallel hybrid [4]

Some of the advanced technologies typically used in hybrids include:

- Regenerative Braking - The electric motor applies resistance to the drivetrain, causing the wheels to slow down. In return, the energy from the wheels turns the motor, which functions as a generator, converting energy normally wasted during braking into electricity, which is stored in a capacitor bank.

- Automatic Start/Stop - The engine is automatically shut off when the capacitor is charged. It is restarted when the capacitor charging level is considered low.

- The engine works in the region where there is the better brake-specific fuel consumption (BSFC). The engine provides less power than a conventional engine, and the engine can be downsized, due to its ability to supply energy to the capacitor.

\section{APPLICATION}

The "Hybridus" vehicle has been manufactured by Agrale (Brazil) in partnership with Cummins and Siemens to develop a hybrid bus with an electrical serial system. This bus uses the serial system due to the cost and ease of powertrain controls. This vehicle has been approved in terms of gradeability and startability.

Gradeability is the steepness of an incline that an engine is capable of climbing at an efficient speed.

Startability is defined as the maximum grade at which a fully laden vehicle combination is capable of starting and maintaining forward motion at a certain friction level.

Vehicle feature data:

- Chassis of 15 tons

- ISB 4 cyl 170 cv - Cummins EuroV (125 kW @600 Nm)

- Gradeability: $28 \%$

- Startability: $16.5 \%$ 
Bus images are shown in figure 7 and 8 below.

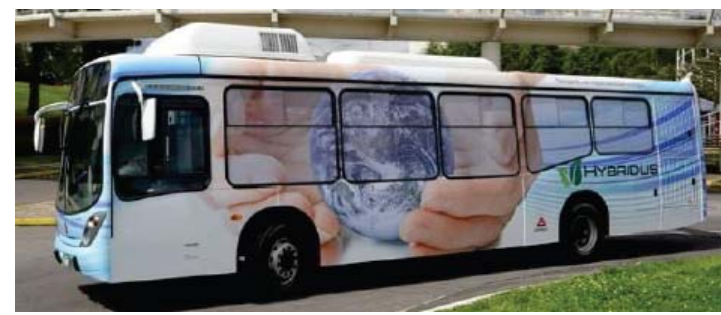

Figure 7: Left-side view of Hybridus bus

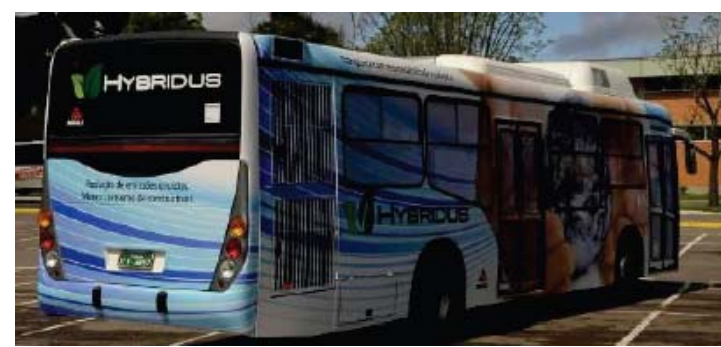

Figure 8: Right-side view of Hybridus bus

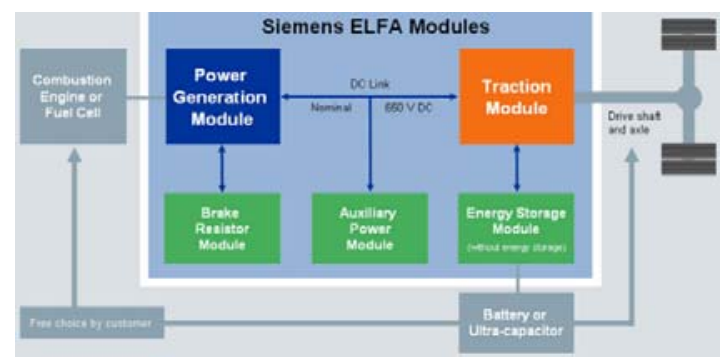

Figure 9: Structure of Hybridus bus [5]

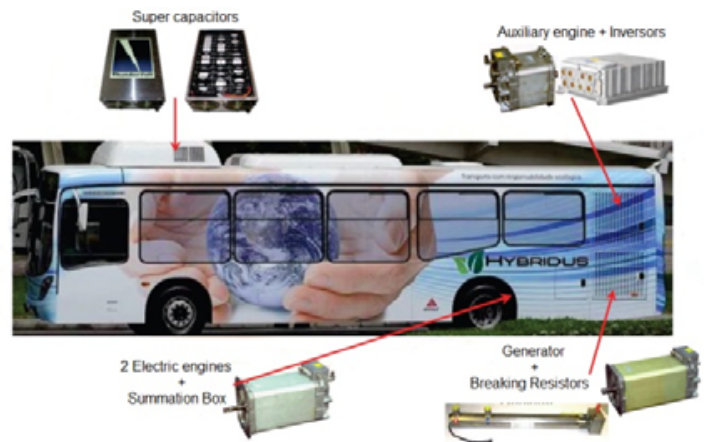

Figure 10: Hybridus bus components

\section{CONFIGURATION}

The components of the electric low floor axle (ELFA) are electric traction motor (induction or permanent magnet), IGBT-based inverters, DCDC converters, generators and control of the hybrid module, as shown in figure 9 and 10.

The engine output is converted into energy using the engine coupled to the generator, and it will be supplied to the electric traction motors, stored in the capacitors or both simultaneously. 
The engine does not have coupled wheels, and with that the engine can work in the region with maximum efficiency. The advantage of the hybrid system in series is the ease of the powertrain control and flexibility in installation.

The duty cycle of the city bus must work at low speed due to car traffic, bus stops and traffic lights.The series hybrid system is more suitable for medium and heavy vehicles due to its simple structure, high performance efficiency, low emission, simple control, low noise and comfort. It has a better use of regenerative braking, and therefore has a good suitability for the bus route in town.

There are two types of electric traction motor for this application, i.e. the induction and the permanent magnet motor; however, the induction motor was adopted in our evaluation due to it being cheaper than the permanent magnet motor. The induction motor is simple, robust and can operate over a wide speed range. If the induction motor is not enough to meet the power required by the vehicle, then two motors can be connected in a summing box.

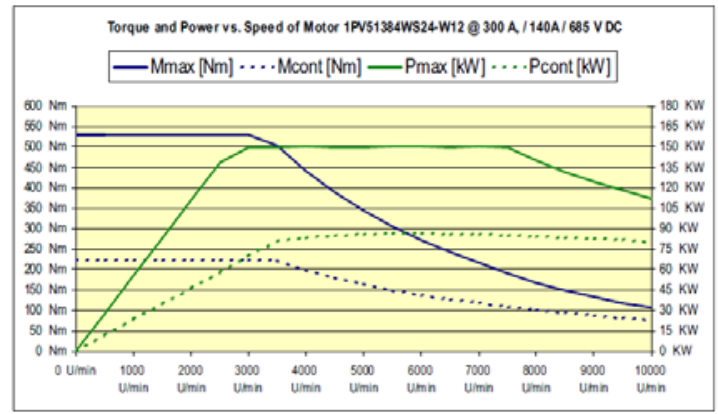

Figure 11: Induction motor torque and power vs. speed [5]

Figure 11 shows the rated power of $85 \mathrm{~kW}$ and rated torque of $220 \mathrm{Nm}$ with 142A of current, but it can reach $530 \mathrm{Nm}$ if the current is 300A. This characteristic allows excellent use of the vehicle at low speed, as acceleration and capture energy are improved when the vehicle is moving slowly.

\section{POWER ELECTRONICS}

The electronic circuit consists of a power rectifier, inverter and DCDC converter (DC to DC converter at different voltage) which are responsible for the connection between the DC (direct current) link voltage and the electronic variable speed motor and generator. The circuit is responsible for controlling the motor, generator and auxiliary drive system. [5]

The DC link is a combination of capacitors and resistors that exists in a rectifier system with the function of stabilising the DC voltage. It consists of an energy buffer that can supply a load or regenerate energy back to the net, and balance and discharge voltage distribution during power down.

Braking resistors can be connected to the fourth phase of the inverter and controlled by switching the insulated gate bipolar transistor (IGBT) inverters on and off. 
During regenerative braking, the resistors are utilised when the ultra-capacitors can no longer absorb energy.

The excess energy is dissipated into the resistor bank and runs the diesel engine (without fuel injection) to dissipate energy and recirculate water into the resistor bank to provide a consistent driving feel to the drive and to ensure vehicle safety. The ELFA system supplies $60 \mathrm{~kW}$, watercooled braking resistors to serve as an auxiliary brake. The resistors turn the kinetic energy into heat that is discharged via the braking resistor water cooling system which is most commonly connected to the combustion engine cooling system. The use of braking resistors also reduces the wear of the conventional mechanical brake and thus decreases the cost and maintenance effort [5].

In addition to generators and electrical traction motors, the ELFA system can also provide an auxiliary motor solution. The auxiliary motor can drive power steering units, air compressors, etc. The auxiliary motor allows an OEM to remove parasitic loads from the internal combustion engine, thus improving the overall efficiency of the system [5].

\section{CONTROL ARCHITECTURE}

The communication of the drive system controller (DICO) with the various electronic units of the vehicle is done via the controller area network (CAN) bus. The DICO works not only as a gateway between the controllers of the ELFA drive system and the electronic units of the vehicle, but also as a supervisory powertrain controller that controls the operation of the hybrid system, monitors the system status and manages communications. It can communicate with the engine control unit (ECU), the braking system (i.e. ABS and traction control unit), the electronic vehicle control unit (EVCU) and the energy storage management unit. These units are normally provided by bus manufactures or suppliers and transfer data to the DICO via the standard SAE J1939 protocol as shown in figure 12.

Based on the drive input (accelerator pedal, brake pedal, etc.) as well as the state of other components, the DICO determines the desired outputs to be generated, such as motor speed and engine torque. These desired output signals are sent to the corresponding controllers (e.g. ECU, EVCU, ELFA inverter, etc.) and become the commands for these units [5].

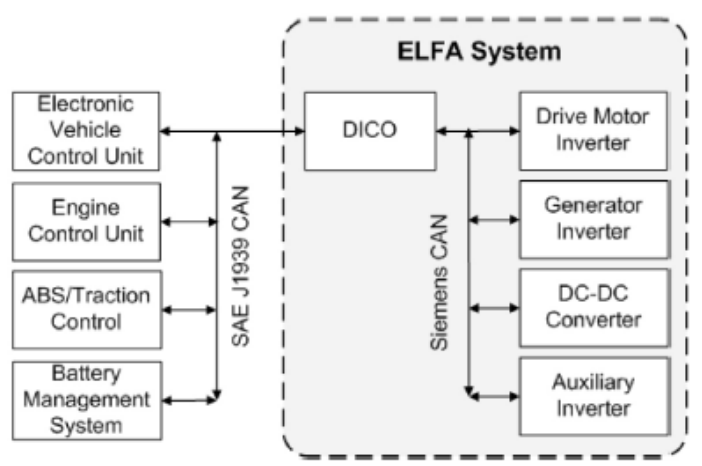

Figure 12: Control architecture of a hybrid electric vehicle [5] 


\section{CONTROL STRATEGY}

The ELFA hybrid system considers two components on a vehicle:

- Power source (PS), which generates power. This can be a generator driven by an engine or a fuel cell;

- Energy source (ES), which is capable of storing energy and could be a battery or an ultracapacitor.

The control strategy needs must determine the power distribution between the PS and ES, so that the power requirements and other constraints are satisfied. The main objective of the controller is to meet the power demand required by the driver, while at the same time maintaining the ES state-of-charge (SOC). To achieve the above objectives, many kinds of control strategies for series hybrid electrical vehicles have been proposed and developed. Some strategies such as global optimisation cannot be used in practice because of the need for a prior knowledge of future driving conditions.

As driving conditions in the future are unknown, as well as information about the PS or the ES, which will be determined by customers, the ELFA system uses a simplified equivalent method by analysing the ES SOC. Simply speaking, the influence of the SOC to the generator power is through the shift of the generator traction power curve. If the SOC decreases, the generator traction curve moves up. In addition to the power required for traction drive, the engine provides extra power to charge the ES and move the SOC back to the optimal operating range. The curve is shifted up due to the low SOC, as shown in figure 13. On the contrary, the curve moves down to prevent the ES from being overcharged when the SOC increases, reducing the power generated. The movement adjusts the generator power and thus stabilises the SOC value of the ES by regulating the relation between engine and traction power.

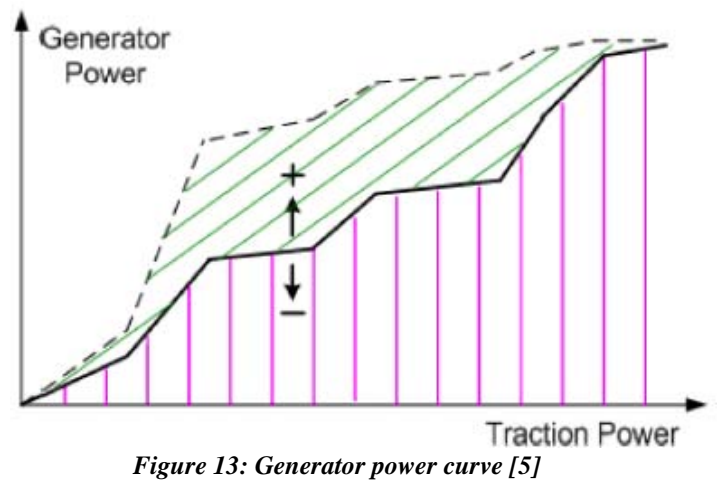

As the PS operation is independent of the vehicle speed, the engine can generate preferred power over many different operating points. After the PS power has been calculated through the energy management algorithm, the control system determines an optimal speed of the engine through a look-up table, which uses the power as input and creates a speed command as an output. However, the PS transient operation can be an important contributor to the vehicle fuel economy and emissions. For this reason, the speed and load of the PS should be changed as little as possible in order to run the PS more efficiently. A power hold function was developed, which modifies the generator power rather than adapting the generative power continuously to the drive power request. 
The ELFA hybrid system can also run with the PS completely off. The engine can be directly turned on or stopped by the generator. This allows the engine to be shut off during coasting and braking, and at all vehicle stops. When more power is needed, the engine can be started in a very short time by the attached generator. Other factors are also taken into consideration, including SOC, braking power, auxiliary system loads, etc.

The DC link is also connected to the ultra-capacitor system through an inductor. The ultracapacitor provides power to the DC link when accelerating the vehicle, but when braking, the traction motors are operated as generators feeding power back into the ultra-capacitor system. The auxiliaries of the vehicle are attached to the auxiliary motor which is connected to the DC link via its own ELFA inverter.

Table 1 shows the fuel savings from different advanced technologies used in the ELFA system. Due to the large kinetic energy of the bus, significant energy can be recuperated through regenerative braking and stored in the ES device. Another important fuel efficiency increase comes from the idle reduction function. This feature not only shuts down the engine at vehicle standstill but also during driving, as long as the ES can provide the required traction power.

Table 1: ELFA system fuel saving summary [5]

\begin{tabular}{|l|c|}
\hline ELFA System Technology & Fuel Saving (\%) \\
\hline Use of regenerative braking & 20 \\
\hline Hybrid energy management control & 6 \\
\hline $\begin{array}{l}\text { Anti-idling and engine shutoff } \\
\text { technology }\end{array}$ & 10 \\
\hline Optimal auxiliary system & 4 \\
\hline Total Savings & $\mathbf{> 4 0}$ \\
\hline
\end{tabular}

This function delivers remarkable fuel efficiency during rush-hour traffic, characterised by multiple stops and low-speed travel.

This function requires independently driven accessories. While it is possible to operate the engine along its optimal points, the energy management strategy will only contribute to moderate fuel efficiency improvements as a consequence of the constraint of engine emissions and noise, degree of passenger comfort and the capabilities of other drivetrain components. The electrification of auxiliaries saves fuel as the auxiliary system can be operated only when needed. The OEMs can further improve the fuel efficiency by downsizing the engine, installing more efficient tyres, etc. However, the actual fuel economies vary depending on the complete bus design and numerous other aspects: the ES device, the selected engine types and sizes, vehicle overall costs, controls, operating philosophy of the auxiliary system, driver behaviour, bus routes and environment.

\section{TEST RESULTS}

The tests were performed on the bus (Agrale) in two different locations: Caxias do Sul, Brazil (city route) and Santiago, Chile (city route). The improvements in fuel consumption were $23.8 \%$ in Brazil and $23.0 \%$ in Chile according to figures 14 and 15. 


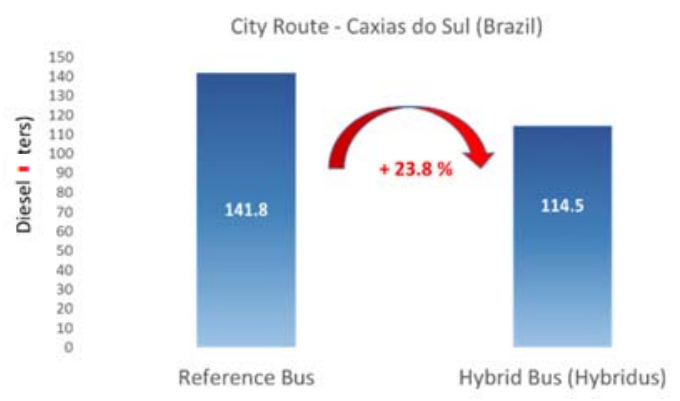

Figure 14: Fuel consumption in Caxias do Sul (Brazil)

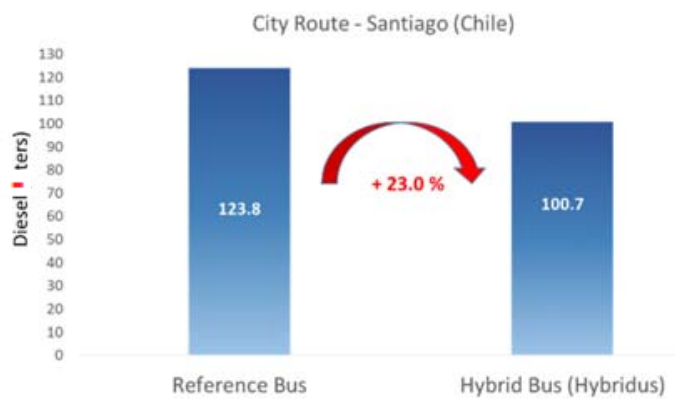

Figure 15: Fuel consumption in Santiago (Chile)

\section{CONCLUSION}

As the price of fuel is continually increasing, the series hybrid system is a viable alternative mode of transport which reduces fuel consumption and emissions. The hybrid vehicle will be a trend for the future as it is the only way to achieve control of the level of emissions. As a consequence, it will also reduce fuel consumption, as shown in figures 14 and 15. Currently the cost of the hybrid system is very high due to low production, but if there was a government incentive to implement the hybrid system in the fleet of trucks and buses, the sale price would be reduced as the sales volume increases.

\section{FUTURE WORKS}

There are more than 1500 ELFA hybrid drive systems available around the world. There are two major types of motors for vehicle applications: induction and permanent magnet motors. Induction motors were used during the tests on vehicles, but there is a plan to replace the induction motor with a permanent magnet motor and compare the difference between them. The permanent magnet is expected to be more effective than the induction motor.

The plan is to acquire emission data from nitrogen oxides $\left(\mathrm{NO}_{\mathrm{x}}\right)$, hydrocarbons $(\mathrm{HC})$ and carbon monoxide $(\mathrm{CO})$ during the duty cycle, and to measure the decrease in emissions. 


\section{REFERENCES}

[1] LOPES Juliana, POMÍLIO José A., "Gerenciamento ótimo de potência de um ônibus elétrico híbrido série para transporte urbano" - CBA, 2010

[2] CARVALHO Carlos Henrique R., FURTADO Bernardo, NADALIN Vanessa, LUEDEMANN Gusavo, 2014, "Poluição Veicular Atmosférica" - pp. 8-14

http://www.cnt.org.br/Imagens\%20CNT/PDFs\%20CNT/comunicado_ipea220911.pdf - Date: $03 / 26 / 2014$

[3] SERPA Eduardo Luis, 2011, "Emissões veiculares no estado de São Paulo 2011" http://www.cetesb.sp.gov.br/ar/documentos/Relatorio_de_Emissoes_Veiculares_no_Estado_ de_Sao_Paulo_2011.pdf - Date: 03/26/2014

[4] LUZ David Queiroz, PAULA JUNIOR Gilmar Alves, 2009, "Fuel Economy Impact Evaluation of Hybrid Vehicles Implementation in the Brazilian Fleet", SAE Paper, 2009-360334

[5] XIAOLAI He, MUNARI Brian, ORBERGER Thomas, NELKE Joshua, 2011, "Siemens ELFA Drive System for Hybrid Electric”, SAE Paper, 2011-01-2195.

\section{ACKNOWLEDGMENTS}

The authors would like to acknowledge Frederick Gonçalvez Claudino and Thiago Guandalini Cunha for their technical support. Thanks also go to Flavio G. Lehmann for contributing his insights and experience. 